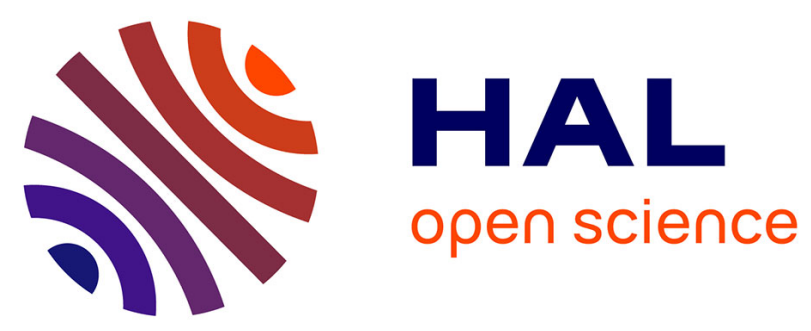

\title{
Iterative Improvement of Process Planning Within Individual and Small Batch Production
}

\author{
Christina Reuter, Timo Nuyken, Stephan Schmitz, Stefan Dany
}

\section{To cite this version:}

Christina Reuter, Timo Nuyken, Stephan Schmitz, Stefan Dany. Iterative Improvement of Process Planning Within Individual and Small Batch Production. IFIP International Conference on Advances in Production Management Systems (APMS), Sep 2015, Tokyo, Japan. pp.283-290, 10.1007/978-3319-22756-6_35. hal-01417489

\author{
HAL Id: hal-01417489 \\ https://hal.science/hal-01417489
}

Submitted on 15 Dec 2016

HAL is a multi-disciplinary open access archive for the deposit and dissemination of scientific research documents, whether they are published or not. The documents may come from teaching and research institutions in France or abroad, or from public or private research centers.
L'archive ouverte pluridisciplinaire HAL, est destinée au dépôt et à la diffusion de documents scientifiques de niveau recherche, publiés ou non, émanant des établissements d'enseignement et de recherche français ou étrangers, des laboratoires publics ou privés. 


\title{
Iterative Improvement of Process Planning within Individual and Small Batch Production
}

\author{
Christina Reuter ${ }^{1}$, Timo Nuyken ${ }^{1}$, Stephan Schmitz $^{1}$, Stefan Dany ${ }^{1}$ \\ ${ }^{1}$ Laboratory for Machine Tools and Production Engineering (WZL), RWTH Aachen Universi- \\ ty, Aachen, Germany \\ \{c.reuter, t. nuyken, st.schmitz, s.dany\}@wzl.rwth-aachen. de
}

\begin{abstract}
Present challenges of small batch production are represented by the need to improve time-to-market and the reduction of costs. A promising approach to take up these challenges is the use of highly iterative development processes such as Scrum known from software development. A transfer of these principles to process planning enables the prediction of producibility of customer orders by iteratively learning from manufacturing data of similar jobs from the past. Based on the required data structures described in this paper, work plans for new orders can be generated automatically. The potential of the approach is validated by an industrial example.
\end{abstract}

Keywords: Computer automated process planning (CAPP); Production planning; Producibility Prediction

\section{Challenges in production planning within individual and small batch production}

In projects that WZL of RWTH Aachen University conducted with industrial partners with individual and small batch production, it was found that process planning is time-consuming and the quality of planning strongly depends on the individual level of knowledge of the responsible employee. One way to face these challenges are computer-automated process planning systems. At this point, it became clear that it is very difficult to transfer the process planners' tacit knowledge to computer-aided planning systems.

As "process planning is the link between product design and product manufacturing and re-manufacturing", it is a central lever for reduction of costs and to improve time-to-market [1].

Wiendahl et. al. postulate following key enablers for an efficient and flexible generation of process plans [2]: cognitivability, evolvability, adjustability, granularity, automation and ability.

The approach presented in this paper especially focusses on cognitivability and automation ability. Therefore, the aim is to introduce a concept for the iterative improvement of process planning by using data from manufacturing. Data structures that

adfa, p. 1, 2011.

(C) Springer-Verlag Berlin Heidelberg 2011 
are prerequisite for an implementation are explained. Moreover, it is shown how comparative advantages can be generated.

\section{Deficiencies of existing approaches}

In recent years the concept of manual process planning in individual and small batch production has been enhanced by computer-aided approaches. As shown in figure 1, Computer-Aided Process Planning (CAPP) systems can be further classified in relation to their degree of automation: Variant process planning, semi-generative process planning and generative process planning [3].

Manual process planning implicates the permanent creation of new work plans which are derived from current or former plans. The process planner therefore conducts an analysis based on the specific product features and CAD data [4]. This continual re-creation of work schedules is very time-consuming. Moreover, the degree of standardization suffers because of the great dependency on preferences and expertise of the production planner.

The basic principle of variant process planning has evolved from manual process planning. It includes the allocation of the product range into part families which are based on similarities regarding functionalities, design features or manufacturing processes and comprise similar pre-determined parameters. Each part is related to a unique part family code which contains all the relevant data of the features of the specific family and the corresponding standardized process plan [5].

The classification of part families is challenging due to the great variety regarding features and combined characteristics of a product. The lack of classification of novel products can cause a problem with the creation of work plans under the condition that structural changes occur. Consequently the system has to be re-aligned. This means that variant process planning still depends on the process planners' expertise and knowledge.

The semi-generative process planning extends the variant process planning by the possibility of structural changes based on a master plan which is altered by the required new process operations. It combines variant process planning with an algorithmic procedure which is supported by CAD models, databases, decision trees, knowledge rules and heuristics [6]. Both, variant process planning as well as semigenerative process planning still rely on pre-defined results of earlier planning operations. Moreover, semi-generative process planning systems are not able to cover all part varieties and still depends on operational involvement of the scheduler.

Generative process planning implicates the generation of work plans which are derived from relevant process and product data. This requires knowledge of all relevant information such as restrictions and dependencies as well as transparency over production processes which can be reached by the use of complete and reliable mathematical models. A truly generative process planning system has not been realized yet [6].

Although the effort for manual creation of work plans is constantly minimized by an increasing degree of automation from manual creation of work plans to generative 
process planning, however, there is still time and effort needed for the definition of rules and regulations.

The initial creation of a set of rules is still possible with great expenses in a static system of production. The real market environment of individual and small batch production is determined by an ever-changing and dynamic system. An exemplary scenario of changing machinery illustrates the consequences of this dynamic. When changing the machinery during the creation of rules and regulations, it is necessary to re-check and adjust the resources again, due to the complexity and interdependency of the existing rules. The additional effort necessary here is similar to the initial definition of the rules. Thus, the initial set of rules and regulations already becomes obsolete during its process of creation. This indicates that for the computer-automated generation of work plans in the individual and small batch production a new approach is crucial.
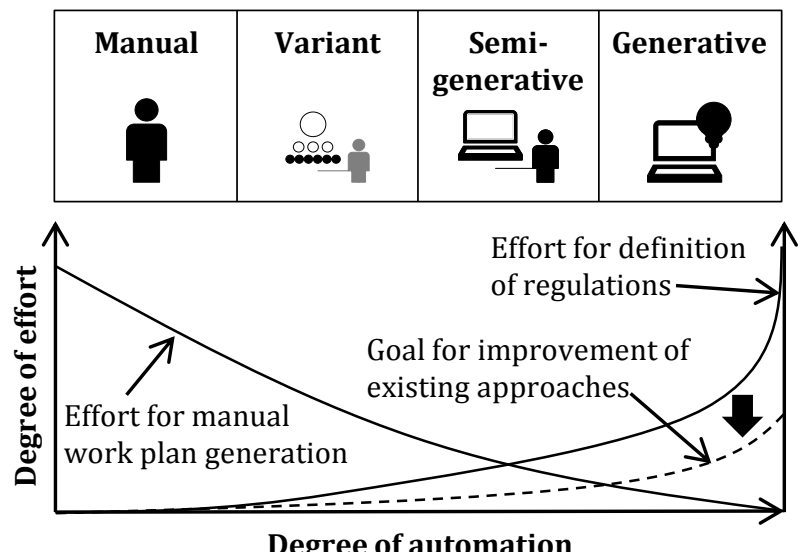

Degree of automation

Fig. 1. Comparison of the described process planning methodologies

The goal for the optimization of existing approaches is the reduction of effort for the initial definition and administration of regulations in generative process planning and to enhance planning quality.

\section{Approach}

The core idea of the presented approach is the iterative use of feedback data from manufacturing in order to improve process planning. According to geometrical, material and functional properties of an individual or small batch product the optimal manufacturing process as well as the optimal machine is identified. Furthermore, standard times for all processes are calculated by using feedback data. As a consequence, the planning quality can be improved und at the same time the planning effort is reduced respectively. 
The quality of planning is measured by an appropriate selection of the manufacturing process and machine as well as the accuracy of the calculated standard times. The planning effort in turn is measured by the time required to generate a work plan. It is required that the approach enables a quick response towards customer requests.

Therefore, in an iterative process like it is known from the Scrum method, data from manufacturing is used for an iterative improvement of CAPP. The Scrum method is a framework which is commonly applied in product development processes. It supports solving complex adaptive tasks and enables to productively and creatively deliver goods with the highest possible value [7].

Based on a generic order fulfilment process, there are three core elements of the approach, which are shown in figure 2 . The core elements are:

1. Iterative improvement of process planning

2. Data management

3. Producibility Prediction

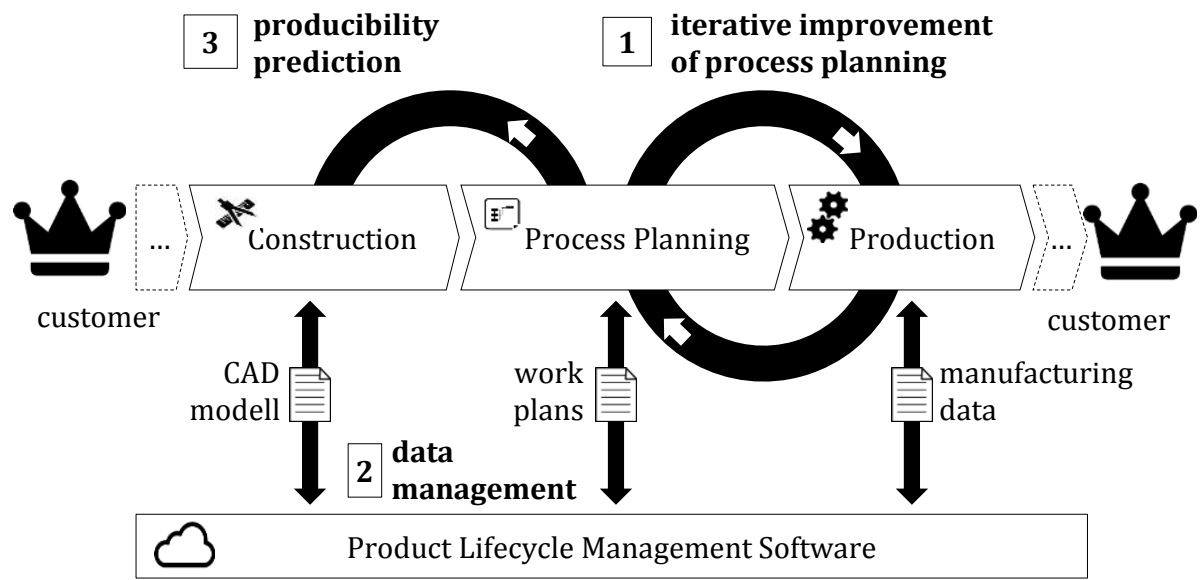

Fig. 2. Concept of iterative improvement of process planning

\subsection{Iterative improvement of process planning}

In order to improve current CAPP systems, a definition of specifications and rules is necessary. Hereinafter, both are referred to as process planning regulations. These process planning regulations facilitate to model manufacturing technologies and processes virtually. For each manufacturing process specific parameters describing the physical procedure are determined (e.g. cutting speed). Furthermore, maximum product dimensions that can be processed as well as tolerance values have to be defined (e.g. accessible surface roughness in face turning process). All parameters and specifications are stored in a technology database.

Based on geometrical, material and functional specifications of a product and using the process planning regulations, an adequate allocation of manufacturing process and machines is achieved. In contrast to given approaches, the allocation is not done 
product by product but rather based on generic product specifications. On basis of data from manufacturing, it is possible to identify standard times based on the defined parameters for all manufacturing processes.

To introduce the iterative process, experienced production planners establish initial specifications for each machine and determine initial values for the required parameters. In the second step an initial work plan is created based on the previously defined process planning regulations. Data raised during the production of the first products and batches enables an iterative improvement of the process planning regulations by comparing the planed and realized production plans. In this way, work plans for the same or similar products can be generated easily in the future. Smart algorithms analyze all data from production, cluster production plans according to similar geometrical and functional specification of products and ensure an iteratively improvement of realizing production jobs.

In case an inadequate work plan is generated for a new product with similar material, geometrical and functional specifications as a production job in the past, the approach described above shows the following advantage: In current CAPP systems the regulations have to be reviewed manually in case of inadequate work plans are generated. Firstly, it has to be analyzed why another machine has been used. Secondly, changes in process planning regulations need to be derived and the necessary changes must be implemented. However, by iteratively using manufacturing data to improve process planning, the smart algorithms mentioned above automatically adjust process planning regulations.

Depending on the type of error in the automatic generation of work plans the following types of adjustments are differentiated:

On the one hand, in case the generative creation of a work plan resulted into the right selection of manufacturing processes and machines but there have been deviations regarding the standard times, the consequent corrective measure must be the alignment of parameters in the technology database.

On the other hand, in case the scheduled manufacturing process is not possible due to wrong determinations in the work plan, it is required to update the machine specifications or to introduce additional process planning rules for the specifications of the customer order.

The binding requirements for an iterative improvement are dependent on a sufficient level of detail of manufacturing data. Only if data from production for similar customer orders are collected under consistent conditions such as machine availability, staff availability and utilization of production, they can constitute a basis for optimization of process planning regulations. Hence, only data that has not been raised during a disruption (e.g. failure of machine) in the production can be considered for an iterative improvement of the process planning regulations. Data sets that have been gathered according to these conditions are flagged in the database. 


\subsection{Data management}

The iterative improvement of production planning requires data from various sources which are stored and administered in a product lifecycle management (PLM) software to ensure a "single source of truth" [1]. The data transferred to the PLM systems in the construction process, in process planning and the production process are shown in figure 2.

The classification of products regarding their geometrical specifications is prerequisite for the computer-automated generation of a work plan. The digital model of a product that is crucial to determine its geometric properties is generated during the construction process. This data is stored in the form of a CAD model in the PLM system. Of course, the previously described technology database is also managed by PLM system.

Furthermore, an iterative improvement of process planning is based on data from sensors in production. As described above, only data that has been recorded in comparable situations can be used for the evaluation. Here, sensors in machines and their surrounding can provide a real-time state description of the component and its environment.

Also, the customer order has to be saved in the PLM system. The combination of geometrical specifications of a product and information from the customer order (e.g. batch size) can influence the selection of manufacturing processes and machines.

\subsection{Producibility Prediction.}

By applying the approach it is possible to provide high-quality information upstream the order fulfillment process. This is referred to as "producibility prediction" (see figure 2).

A key advantage of a computer-automated process planning is to enable the constructor to review his/ her design quickly with respect to feasibility and effort in production. The experience of these feedback loops can be derived into construction guidelines. Based on this feedback and analogous to the iterative improvement of prototypes in product development by applying an iterative process, a construction that meets the requirements can be created easier. Hereby, time-to-market as well as planning costs can be reduced. It is also possible to provide fast feedback about the producibility of a customer request, which also shortens time-to-market and may generate a competitive advantage.

\section{Case study and validation}

The approach is validated with an industrial partner. The company is a leading global manufacturing company for blades, brakes and clutches and offers individual products for forming domains, general mechanical engineering, mobile applications in construction machine industry as well as within the rural economy. The offered product range includes about 40.000 various components, each with up to 70 different 
variants. As a consequence, the process planning faces a high product variety and the planning quality highly depends on the planner's practical experience.

The validation is realized within two steps: In a first step, the initial situation is documented with regard to planning quality and quality effort. In the second step, the potential of the approach is estimated. The results are summarized in figure 3.

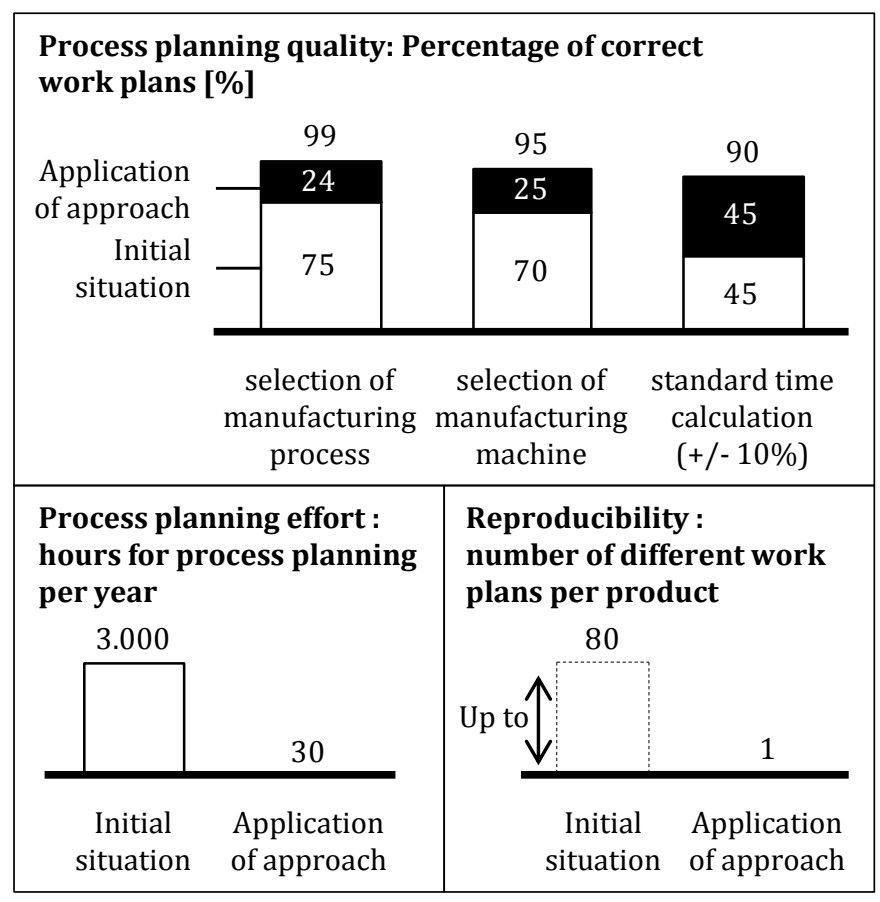

Fig. 3. Initial situation and potential of the approach

Analyzing the results, planning effort can be reduced, reproducibility can be increased and the process planning quality can be improved in a high extent. Experts of industry especially expect a high improvement potential for the calculation of standard times. The planning quality can be considerably enhanced by adjusting the parameters in the technology data base iteratively with the use of an automatically evaluation of data from manufacturing process. Initially, in $75 \%$ of the cases the correct manufacturing method is selected. Taking the new approach for iterative improvement of process planning, the percentage of correct work plans can be increased up to $99 \%$. The potential for the selection of an adequate manufacturing machine is estimated similarly high. Expenses for the manual creation of work plans can be almost completely eliminated with the approach.

The experts consider reproducibility to be particularly important. By applying the approach, the planning process is independent of the individual expert knowledge of the employee and work plans are a reliable input for Production Planning. 


\section{Conclusion}

The approach of this paper transfers iterative improvement principles known from product development such as Scrum to process planning. It is proposed to use data from manufacturing to enable and improve current CAPP systems. By applying the three elements of the approach, it becomes possible to reduce efforts for process planning and to improve time-to-market. For validation, the approach was discussed with experts from industry to validate its potential.

Further work needs to be done to detail the presented approach: In a next step smart algorithms that are crucial for the iterative improvement of process planning regulations should be developed and detailed. Further research is needed to implement producibility prediction to provide valuable information for the constructor.

Acknowledgement. The authors would like to thank the German Research Foundation DFG for the kind support within the Cluster of Excellence "Integrative Production Technology for High-Wage Countries".

\section{References}

1. ElMaraghy, H., Schuh, G., ElMaraghy, W., Piller, F., Schönsleben, P., Tseng, M., Bernard, A., 2013, Product variety management, CIRP Annals - Manufacturing Technology, 62/2: 629-652

2. Wiendahl, H.-P., ElMaraghy, H.A., Nyhuis, P., Zäh, M.F., Wiendahl, H.-H., Duffie, N., Brieke, M., 2007, Changeable Manufacturing - Classification, Design and Operation, CIRP Annals - Manufacturing Technology, 56/2: 783-809

3. Marri, H. B., Gunasekaran, A., Grieve, R. J., 1998, Computer-aided process planning: A state of art, The International Journal of Advanced Manufacturing Technology, 14/4:261268

4. Salehi, M., Tavakkoli-Moghaddam, R., 2009, Application of genetic algorithm to computer-aided process planning in preliminary and detailed planning, Engineering Applications of Artificial Intelligence, 22:1179-1187

5. Hazarika, M., Dixit, U. S., 2015, Setup Planning for Machining, Springer, Cham Heidelberg New York Dordrecht London

6. ElMaraghy, H., 2009, Changing and Evolving Products and Systems, Springer, London

7. Schwaber, K., Beedle, M., 2002, Agile Software Development with Scrum, Prentice Hall, Upper Saddle River 